\title{
Mulheres e resistência em $O$ país sob minha pele, de Gioconda
}

\section{Women and resistance in The country under my skin by Gioconda Belli}

\author{
Joelma de Araújo Silva RESENDE* \\ Instituto Federal de Educação, Ciência e Tecnologia do Piauí (IFPI) \\ Raimunda Maria DOS SANTOS** \\ Universidade Federal do Rio Grande do Sul (UFRGS) \\ Sebastião Alves Teixeira LOPES ${ }^{* * *}$ \\ Universidade Federal do Piauí (UFPI)
}

RESUMO: O objetivo dessa pesquisa é investigar a participação da mulher no movimento revolucionário na Nicarágua, a partir do livro de memórias $O$ país sob minha pele, de Gioconda Belli, escritora nicaraguense que participou do movimento sandinista, que derrubou a ditadura de Somoza. Para isso, foi feita uma análise da relação entre mulher e nação, dando-se ênfase à participação feminina na luta contra a ditadura. Para tanto, cita-se Zinani (2010), que aborda os escritos femininos sobre ditadura, Mattoso (2010), que retrata a identidade nacional, e Walby (2000), que analisa a relação entre mulher e nação. Percebe-se que a mulher tenta conquistar um espaço na vida social, lutando pelo que considera mais justo para seu país, sendo assim, agente de transformação social. Percebe-se também que, apesar de não reconhecida pela historiografia oficial, a mulher participa do projeto de construção nacional na Nicarágua, como demonstrado por Gioconda Belli.

PALAVRAS-CHAVE: Memória. Resistência. Nicarágua. Ditadura. Mulher.

ABSTRACT: The aim of this research is to investigate women's participation in the Nicaraguan revolutionary based on the memoir book The country under my skin: a memoir by

\footnotetext{
* Professora de Língua Portuguesa no Instituto Federal do Piauí (IFPI). Mestre em Letras, área de Literatura, pelo Programa de Pós-Graduação em Letras (PPGeL) da Universidade Federal do Piauí (UFPI). Teresina-PI. E-mail: joelmadearaujosilva@gmail.com

** Professora de Literatura na Universidade Federal do Piauí (UFPI). Doutoranda em Letras: Estudos de Literatura na Universidade Federal do Rio Grande do Sul (UFRGS), quadriênio: 2019/2023. Porto Alegre-RS. E-mail: professorarai@ @otmail.com.

**** Doutor em Letras, Área de concentração: Língua Inglesa e Literaturas Inglesa e Norte-Americana, pela Universidade de São Paulo (2002); Pós-Doutorado na Universidade de Winnipeg, Canadá (2007); PósDoutorado na Universidade de Londres/School of Oriental and African Studies, Inglaterra (2014). Atualmente é professor Associado da Universidade Federal do Piauí. Teresina-PI. E-mail: slopes10@uol.com.br.
} 
Gioconda Belli, a Nicaraguan writer who participated in the Sandinista movement which overthrew Somoza's dictatorship. Thereunto, an analysis of the relationship between women and nation was made, with emphasis to female participation on the struggle against dictatorships. Therefore, Zinani (2010) who approaches women's writing on dictatorships, Matoso (2010) who portrays national identity and Walby (2000) who analyzes the relationship between women and nation are quoted. It is realized that women try to acquire a space in social life, battling for what they assume most fair for their country, thus, as agents of social transformation. It is also clear that women participate in Nicaragua's national construction project despite of not being recognized by official historiography, as it is demonstrated by Gioconda Belli.

KEYWORDS: Memory. Resistance. Nicaragua. Dictatorship. Woman

\section{Introdução}

Gioconda Belli é uma escritora nicaraguense que fez parte da Frente Sandinista de Libertação Nacional (FSLN), organização que se opunha à ditadura da família Somoza na Nicarágua. Nessa organização, Belli trabalhou clandestinamente como correio, transportou armas e viajou pela Europa e América Latina para divulgar a causa sandinista. O país sob minha pele (2001) é um texto de memórias de Belli sobre a ditadura na Nicarágua. Além deste texto, Belli escreveu poemas, considerados polêmicos por exaltarem o corpo e a sensualidade feminina; escreveu, dentre outros, Sobre la grama (1972), conquistando o prêmio Mariano Fiallos Gil da Universidade Nacional Autónoma de Nicarágua (UNAM); Línea de fuego (1978), escrito enquanto estava exilada no México e com o qual ganhou o prêmio Casa das Américas; La mujer habitada (1978), muito bem recebido pela crítica e traduzido em 11 idiomas; El ojo de la mujer (1991); El infinito em la palma de la mano (2008), novela que ganhou os prêmios da Biblioteca Breve de Novela 2008 da editorial espanhola Seix Barral e o Sor Juana Inés da Cruz da Feira Internacional do Livro de Guadalajara; El país de las mujeres (2010); El intenso calor de la luna (2014), dentre outros.

Em seu texto de memórias, Belli narra a trajetória percorrida pelo país para que a Nicarágua se libertasse do clã Somoza. Durante décadas, o país sofreu com a ditadura 
imposta por essa família e Belli, apesar de todo o contexto patriarcal em que vivia, decide lutar pela liberdade de seu país. As investigações realizadas sobre a obra de Belli, principalmente sobre $O$ país sob minha pele, sempre apresentam a autora como alguém que busca sua identidade como mulher e como sujeito que procura a liberdade para seu país.

Procurou-se, assim, nesta pesquisa, uma análise de $O$ país sob minha pele em especial no que diz respeito à participação da mulher na construção de uma identidade nacional na Nicarágua, procurando mostrar o quanto a mulher se empenhou na busca pela liberdade de seu país, participando inclusive da luta armada. Para tanto, apoia-se em Zinani (2010), Mattoso (2010), Walby (2000), Zimmermann (2006), Randall (1982), dentre outros pesquisadores.

Segundo Zinani (2010), a temática da ditadura tem sido trabalhada na América Latina desde o início do século XX. O tema tem sido aproveitado por escritores que utilizam a obra de arte para promover a reflexão sobre o tema. A partir dos anos 1980 surgem, de maneira expressiva, obras de mulheres que relatam suas vivências e suas relações com o social e o político. Entre essas mulheres destaca-se Belli, que relata a ditadura vivida na Nicarágua, enquanto o país era comandado pela família Somoza. Para realizar o estudo, partiu-se do questionamento: como a mulher tem participado de movimentos revolucionários?

Para responder a questão proposta busca-se, através de uma metodologia descritiva bibliográfica, aclarar a força do nacionalismo em um contexto de luta, a força das mulheres e da literatura diante de importantes revoluções históricas. $\mathrm{O}$ foco da pesquisa volta-se para a ficção memorial de Belli e para os acontecimentos históricos da Nicarágua que correspondem às representações em $O$ país sob minha pele.

\section{Literatura e resistência feminina}

Na ditadura da América Latina, muitos atos de repressão são cometidos. Torturas, assassinatos e inúmeros desaparecimentos são praticados sob o pretexto de manter a ordem no país. A Literatura busca tematizar esse período de sofrimento: "a necessidade de registro ficcional é apontada como solução para aquilo que ultrapassa o conceito, pois o entendimento também depende de uma coerência formal que, às vezes, 
somente é obtida através da ficção" (ZINANI, 2010, p. 128). Portanto, ao ser transposto para o texto literário, o evento ditatorial é transmitido de maneira mais eficaz que um simples relato que não possui a força de um texto ficcional. Zinani acrescenta que a literatura produzida por mulheres tem tido um espaço importante nas discussões sobre gênero. Antes privada no ambiente doméstico, aos poucos a mulher vai ganhando espaço e passa a escrever obras de qualidade. Sobre a temática da ditadura na escrita feminina, Zinani afirma:

Na abordagem feminina da ditadura, constata-se a apresentação de um caráter testemunhal dos eventos narrados, o qual aproveita a memória individual e coletiva, a fim de construir, a partir de pequenos relatos, a história não oficial dos acontecimentos agora transfigurados em ficção. (ZINANI, 2010, p. 46).

A referida autora expõe que a relação entre memória e ditadura é relevante para duas áreas: literatura e história. No contexto da produção literária, a memória se transforma em narrativa. No caso de países que sofrem períodos de ditadura, a reconstituição da memória nacional é de extrema importância para as fontes históricas e literárias e contribui para construção de uma nova memória nacional. "Belli consegue se apropriar da realidade e transformá-la em matéria literária" (ZINANI, 2010, p. 103). É possível rever a história, através da obra de arte e para isso a autora utiliza a memória individual e a memória histórica.

Entende-se que há mulheres nicaraguenses que apresentam uma forte ligação com o país, a ponto de arriscar sua vida, renunciar a família, em busca de um futuro livre para a Nicarágua, um sonho coletivo. Belli identifica-se de maneira muito forte com sua nação e isso a faz correr riscos e sofrer renúncias para lutar por seu país. De acordo com Mattoso (2010, p. 3), "a identidade nacional resulta da percepção que os próprios cidadãos têm de formarem uma coletividade humana". A identidade nacional é o resultado de um processo histórico que passou por diversas fases até chegar ao formato que se conhece atualmente.

Randall (1982) escreve que, ao longo dos anos, a mulher latino-americana tem dado sua contribuição para conquistar melhorias na sociedade em que vive. Historicamente não faltam mulheres que lutam pela independência de seu país, contra a ditadura ou em época de guerra. Essas atuações estão quase sempre atreladas à condição de serem mães, esposas, filhas, ou seja, mulheres ligadas a homens que possuem 
posição social importante. Na Nicarágua, diferente de outros países, em que, ao terminar o período de crise, as mulheres retornam ao espaço doméstico, as mulheres mantinham de forma permanente o espaço conquistado. Randall acrescenta que no exército de Sandino ${ }^{1}$ houve participação ativa da mulher. O próprio Sandino destaca em entrevista encontrada no livro Maldito país, a colaboração valiosa que foi dada pelas mulheres nicaraguenses. Elas trabalharam em correio, espionagem, enfermaria, trabalhos domésticos e diretamente no exército. Através de relatos de mulheres que participaram da luta contra a ditadura na Nicarágua, Randall mostra histórias de coragem, sofrimento e desejo de mudança. Os relatos mostram que a mulher de menor condição socioeconômica foi a que trabalhou verdadeiramente no processo revolucionário.

A condição de classe é determinante para a participação dessa mulher que deseja melhores condições de vida para ela, seus filhos e as futuras gerações. No relato de Gloria Carrion, coordenadora geral da Associação de Mulheres Nicaraguenses Luisa Amanda Espinosa (AMNLAE), há a descrição da atuação das mulheres nesse período:

\begin{abstract}
A mulher, como pilar do lar, é a que está mais ligada econômica, psicológica e emotivamente à criação e educação dos filhos; e isso motivou a mulher a lutar em defesa da vida de seus filhos e em defesa da juventude em geral. Porque a mulher jovem se motiva pelo que é motivada a juventude em geral, mas a mulher um pouco mais velha foi motivada, muitas vezes, pela defesa de seus filhos. Há um cordão umbilical entre a juventude e a mãe. E muitas vezes a mãe começa a participar em tarefas de apoio a seus filhos ou em defesa de seus filhos contra a repressão, o cárcere, a tortura. E, depois, já está integrada e sua participação atinge outros níveis. (RANDALL, 1982, p. 44).
\end{abstract}

No início, segundo Randall (1982), quando as primeiras mulheres decidem ir à luta, o preconceito é muito grande; principalmente porque os pais não aceitam a participação das filhas no movimento, dizem que o homem é que deve lutar. Com os anos, a situação muda, a mulher demonstra que tem o mesmo direito de participação que os homens. Para que essa mudança ocorra, contudo, muitas mulheres são torturadas, violentadas sexualmente, assassinadas e têm seus filhos mortos também. Nora Ostorga, militante sandinista, ressalta as características peculiares da mulher nicaraguense:

\footnotetext{
${ }^{1}$ Augusto César Sandino líder revolucionário nicaraguense que lutou contra a presença militar dos estados Unidos na Nicarágua . Foi executado pelo general Anastasio Somoza García, que comandou a Nicarágua durante mais de quarenta anos, através de um golpe de Estado. A Frente Sandinista de Libertação Nacional (FSLN), que derrubou o governo de Somoza em 1979 foi o legado de Sandino.
} 


\begin{abstract}
A mulher nicaraguense é um ser que sente muitíssimo tudo aquilo que acontece à sua volta. Nunca foi um ser apático. Apesar de não participar, em muitas ocasiões, sempre foi bem receptiva. E há algo mais: ela ama entranhamente seus filhos. Seus filhos e todos os demais. Isto é, nossa mulher é bem afetiva e isso a leva muitas vezes a entrar sentimentalmente, a comprometer-se em algo. Mas, uma vez que entra, vai crescendo com as experiências, com as vivências. (RANDALL, 1982, p. 149).
\end{abstract}

Zimmermann (2006) afirma que, no final da década de 1960, o número de mulheres envolvidas na FSLN aumenta consideravelmente devido à clandestinidade. Nos primeiros anos, o trabalho delas consiste em serviços de limpeza, alimentação, produção de comunicados; com o manuseio de armas e treinamento militar, muda a maneira como os companheiros as tratam e como elas próprias se veem. Mas deve-se lembrar que essas mulheres estão rompendo com convenções sociais ao unirem-se à FSLN.

De maneira geral, o que predomina é o universo patriarcal, em que os homens são os chefes de família e as mulheres ficam em casa, cuidando dos filhos. Dentro da organização, exige-se o uso de calças compridas, que todos durmam de botas, também devem cortar laços com familiares que não fossem da FSLN, além de evitar contato íntimo com companheiro do movimento. Por todas essas exigências, alegam-se medidas de segurança. A vida das mulheres nessa época não é nada fácil. De acordo com Zimmermann (2006), as mães de membros da FSLN que estão presos, trabalham organizando greves de fome e ocupações de prédios. As mulheres do campo têm uma vida árdua; com menos de 30 anos, essas mulheres aparentam ter 40 ou 50 anos, devido aos longos anos de trabalho duro sob o sol e gestações precoces. Muitas são abandonadas por seus maridos, que alegam ir trabalhar na cidade; alguns voltam anos depois para buscar os filhos, que, já crescidos, podem trabalhar.

\title{
2 O país sob minha pele: a mulher no movimento revolucionário da Nicarágua
}

Na Nicarágua, ao longo dos anos, o Movimento de Libertação Nacional luta contra a ditadura somozista. No decorrer desse tempo, é criada uma identidade com o país, não só por parte dos revolucionários, mas por toda a população, que aos poucos começa a ir às ruas reivindicar direitos. Belli cresce ouvindo notícias sobre Fidel Castro; 
na infância, ela e o irmão já se interessam pela temática do patriotismo, fazendo leituras ou cantando o hino dos rebeldes. Ao ouvir o irmão cantar esse hino, ela diz: "Creio que foi ouvindo-o cantar que tive meus primeiros ataques de patriotismo. Repetia a canção pensando secretamente em Somoza, nosso tirano" (BELLI, 2002, p. 23).

Os acontecimentos políticos são um fator decisivo na formação da identidade nacional, mas segundo Mattoso (2010), nem todos os países seguem a mesma evolução; em alguns casos, esses fatores podem ser culturais, econômicos ou sociais. Mattoso escreve que a identidade nacional não é somente um fenômeno mental; apresenta sempre um suporte objetivo. Não se concebe a identidade nacional sem alguma forma de expressão política, sem um espaço determinado e sem que a autonomia política permaneça de forma contínua em um tempo considerável. Para o autor, “o valor atribuído à identidade nacional é tanto mais positivo quanto mais importante se considera a sua defesa como meio de beneficiar os indivíduos que dela participam" (MATTOSO, 2010, p. 19).

Em O país sob minha pele vê-se que os integrantes do Movimento de Libertação Nacional arriscam suas vidas, inclusive muitos morrem em prol da luta por um país com melhores condições de vida para toda a população. A identidade com a luta do movimento vai contagiando o povo e com Belli não é diferente. Ela arrisca-se, deixa a família em segundo plano e aos poucos vai construindo uma relação muito forte com o movimento: "O sandinismo era parte fundamental de minha identidade. Afetivamente era minha família, tão parte de mim quanto meu sobrenome" (BELLI, 2002, p. 114). A sociedade e a família muitas vezes não compreendem esse comportamento de luta da mulher por seu país, em que deixam de lado o comportamento tradicional para defender uma causa coletiva; pois "o normal” para a vida da mulher é seguir seu casamento, criar seus filhos e viver reclusa no ambiente doméstico. Belli vai além disso, quebrando normas e regras e seguindo um caminho de acordo com o que considera justo para seu país.

Em suas memórias, Belli expõe a relação mulher/identidade nacional através do relato de sua participação e de outras mulheres na libertação da Nicarágua do ditador Somoza. Em relação à questão entre sexo e nacionalismo, Walby (2000) cita cinco maneiras de as mulheres se envolverem nesse processo, que são apontadas por YuvalDavis e Anthias: 1) Como reprodutoras dos membros da coletividade; 2) Como 
reprodutoras das fronteiras dos grupos nacionais; 3) Como tendo uma participação central na reprodução das ideologias da coletividade; 4) Como significantes de diferenças étnicas/nacionais; 5) Como participantes ativas das lutas nacionais. Para as autoras, as mulheres comprometem-se com o projeto nacional/étnico tanto quanto os homens, mas às vezes o fazem de maneiras diferentes.

Belli é uma participante ativa da luta contra a ditadura de Anastacio Somoza, encaixando-se na maior parte do tempo no tópico 5 acima. Embora muitas vezes se sinta com medo, o que é considerado normal para uma mulher que tem filhas e não quer deixá-las desamparadas, segue em frente. Independente das consequências, luta por uma Nicarágua mais justa. Esse é o pensamento também de Leana, uma colega do movimento:

\begin{abstract}
Se alguma coisa nos acontecer, terão os pais, a família. Não somos as únicas que podemos criá-los - dizia-me ela- Se pensássemos assim, as mulheres não poderiam participar de nada. Temos que nos cuidar para sobrevivermos, mas não se pode passar a vida com medo de morrer. Quem me diz que não posso morrer amanhã em um acidente? Pelo menos assim morrerei sabendo que fiz algo por eles. E meus filhos saberão. (BELLI, 2002, p. 75).
\end{abstract}

Walby (2000) questiona se o menor militarismo da mulher causa um menor nacionalismo; a autora acrescenta que devido ao fato de serem mais pacíficas, as mulheres têm um compromisso maior com a paz e a cooperação internacionais do que com o nacionalismo militarista. Apesar de se achar que as mulheres são mais pacíficas e Belli dizer que odeia atirar, ela, assim como todos que entravam para o sandinismo, recebe aulas para aprender a manusear armas:

\footnotetext{
A cada disparo meu corpo se descosturava. O estrondo sacudia cada uma de minhas articulações e me deixava na cabeça um assobio insuportável, agudo, desconcertante, saído de quem sabe onde. Eu teria vergonha em admitir o quanto odiava atirar. (BELLI, 2002, p. 21).
}

É nesse momento que Belli conhece Fidel Castro, que fala com ela enquanto manuseava uma metralhadora calibre 50. Ela recosta-se sobre uma cadeira e sua mente gira em uma confusa mistura entre passado e presente. Acompanhou a trajetória de Fidel como revolucionário e o tem como um herói. "Fidel era para mim o símbolo do heroísmo mais puro e romântico" (BELLI, 2002, p. 23). Em um momento anterior, 1974, ela já havia mostrado a aversão que tinha por armas, quando seu amigo Roberto diz que vai lhe dar a primeira instrução militar. Em uma praia, Roberto tira da cintura 
uma pistola enorme, uma P-38. Belli assusta-se com a arma, mas resolve aceitar o desafio: "Roberto [...] indicou-me como sustentar a arma, como posicionar os pés para que o impacto não me desestabilizasse. Fechei os olhos instintivamente quando apertei o gatilho. Pensei que ficaria surda para sempre" (BELLI, 2002, p. 110). Mesmo não se sentindo bem em praticar tal ato, Belli sabe que aprender a atirar é necessário para seguir em frente na guerra pelo seu país.

Para Culver (2013), é comum, nesse contexto de luta, a mulher se sentir pressionada a agir de maneira mais feminina, para sentir-se ou provar que é mulher de verdade, ou sentir a necessidade de ser mais masculina, para assimilar melhor a cultura militar. Em pesquisa sobre o tema, Edwards e Jones (2009) sugerem que a mulher pode revelar duas identidades: primeiro, pode sentir-se insegura em viver de acordo com os ideais masculinos militares, questionando se tem capacidade para agir violentamente, ou se possui atributos físicos para executar tarefas militares, ou ainda se será levada a sério pelos pares masculinos; segundo, a mulher sente-se insegura em relação à manutenção de sua identidade como uma "mulher de verdade". Ao usar estratégias de compensação para essas inseguranças, a mulher passa a usar a máscara, não agindo de maneira natural. Com o tempo, percebe que está perdendo sua identidade e compreende que o uso de uma máscara pode ser prejudicial; assim, reconhece aspectos específicos de sua identidade e passa a tentar agir de maneira autêntica, coerente com seu verdadeiro eu.

Desde pequena, Belli presencia em sua família comentários e discussões a respeito da ditadura. Seus pais são de oposição e a família de sua tia Elena é inimiga da ditadura; ficam discutindo por muito tempo como livrar a Nicarágua desse mal. Ainda criança, percebe os rumores dos adultos afetados com as atrocidades cometidas; certa vez, ouve disparos contra estudantes em que um deles é assassinado. Belli cresce com a consciência de que em seu país não é permitido se expressar. A casa de sua tia Elena limita-se com a casa do Partido Liberal de Somoza; quando realizam comícios, a família tapa os ouvidos para não ouvir 'os vivas' a Somoza:

\footnotetext{
Minha prima Toti gritava "morra" quando na outra casa gritavam "viva". Eu a acompanhava sem elevar muito a voz, ou pedia que se calasse, imaginando que os soldados não demorariam muito em chegar e golpear as portas para nos levar presas. Ouvira dizer que por menos que isso as pessoas iam parar na prisão. (BELLI, 2002, p. 31).
} 
Todo esse contexto juntamente com a mentalidade que possuía, de ser alguém que não deveria submeter-se a imposições e lutar pelo que considerava justo, são cruciais para a identificação de Belli com a causa de seu país.

Embora seus familiares não tenham lutado efetivamente contra a ditadura, ela cresce ouvindo as conversas de seus pais e de sua tia, em que falam contra o ditador. Belli fica sabendo de assassinatos praticados contra quem se manifestava contra Somoza. Certa vez, vê uma mancha de sangue na calçada e sabe que ali havia sido morto um rapaz que lutava por seu país. Todas essas marcas crescem com Belli e a tornam uma mulher comprometida com seu país, com uma Nicarágua livre. Insatisfeita com a situação do país, onde a desigualdade social é enorme, Belli torna-se sandinista. Começa com pequenas ações, mas aos poucos vai fazendo trabalhos cada vez mais perigosos. É vigiada pelo chefe do escritório de segurança somozista, mas, ao ser indagada pelos sócios do escritório onde trabalha, nega que seja sandinista. É seguida por dois meses e por conta de todo seu empenho à FSLN recebe uma carta do sandinista Marcos, que para ela tem um conteúdo muito especial. Ele a comunica que, devido à sua valentia e persistência, conseguiu conquistar o status de militante sandinista. Belli não cabe em si de tanta felicidade e relê a carta inúmeras vezes. Para uma mulher, ser reconhecida por seu trabalho em um ambiente predominantemente masculino era muito importante. Isso significava que era vista por Marcos como uma combatente, com olhar justo e não com o olhar machista, comum em uma sociedade patriarcal.

Em 1977, quando está exilada na Costa Rica, vários ataques sandinistas são planejados contra o governo ditatorial da Nicarágua. Nesse momento, Belli é encarregada de uma missão importante e perigosa: deve levar armas até a fronteira, pois a pessoa que está encarregada disso falha. "Eu estava contrariada. Não entendia por que só na última hora recorreram a mim. Parecia-me uma falta de previsão, um preocupante sintoma de improvisação" (BELLI, 2002, p, 203). Belli somente é encarregada da missão porque a outra pessoa falhou, ou seja, lembram-se dela somente em uma situação emergencial. Apesar de todo seu empenho nas ações do movimento, tudo que passou longe das filhas e de seu país, os sandinistas a tratam como segunda opção para missões mais arriscadas.

Essa situação da mulher, como não participante de decisões em momentos importantes é comum. Belli consegue entregar as armas, mas depois fica sabendo que 
nem todos os ataques que estavam planejados são concretizados. A improvisação dá lugar a falhas que impedem a execução do plano geral; Humberto Ortega, um dos líderes do movimento, diz que, naquele momento, o objetivo não é tomar o poder, mas apenas provocar os ataques e iniciar uma onda de rebeldia. Belli continua fazendo crítica aos ataques, pois inúmeras pessoas estavam sendo mortas, já que não há um preparo adequado para aquelas ações.

Apesar de achar esses ataques improvisados, Belli sente uma excitação em estar participando de missões perigosas. Quando é encarregada de levar as armas e a munição para a fronteira, sente medo, mas ao mesmo tempo mostra-se satisfeita por poder participar daquele momento: “Assombra-me recordar meu sangue-frio, mas a verdade é que no final até senti uma certa excitação. Depois de tudo, desde 1970 preparava-me para fazer coisas como essa" (BELLI, 2002, p. 203). No fundo, acredita que tudo pode dar certo e quando o brasileiro Sérgio, seu esposo, diz que não entende como os sandinistas acreditam que poderão tomar o poder de forma tão rápida, Belli logo argumenta:

\footnotetext{
- Mas, a Frente está há anos nesta luta - argumentei na defensiva. A guerrilha na montanha. O trabalho nos bairros. Não queria mais dúvidas. - Sim, homem, não seja pessimista - dizia. - É que você não sabe como nós nicaraguenses somos. As pessoas são incríveis. E já estão fartas do somozismo. Já são quarenta e tantos anos. Não se esqueça. (BELLI, 2002, p. 204).
}

Com o tempo, Belli passa a envolver-se cada vez mais em atividades perigosas no movimento. Com a rebelião na Nicarágua em 1978, que avança rapidamente, Belli cada vez mais assume grandes responsabilidades na Costa Rica; dirige e coordena as atividades políticas, os partidos e as redes de apoio, além de encarregar-se dos meios de comunicação. Também transporta dinheiro, mensagens e documentos para Costa Rica, Honduras e Panamá. Em 1979, seu trabalho é reconhecido: "O sandinismo se reorganizou no exterior. Designaram-me para fazer parte da Comissão PolíticoDiplomática da FSLN, espécie de embaixadora do que já era um prestigioso e reconhecido movimento de libertação". (BELLI, 2002, p. 279). Belli, mesmo não concordando com a violência implantada nas operações e tendo um receio inicial de entrar no movimento, torna-se disponível para o que seja necessário. Apesar dos abalos com a violência praticada, dos companheiros mortos, continua disposta a lutar: "Foram 
centenas de vidas interrompidas... Eu já não chorava. Nessa época, eram tantas as mortes que não conseguia assimilá-las como certas, as mistificava” (BELLI, 2002. p. 223). Belli sempre lembra o fato de querer estar na luta. Quando Modesto (com quem estava se relacionando) vai para um combate em 1979, em uma cidade ao norte de Matagalpa, que era bombardeada pela Guarda Nacional de maneira incessante, Belli deseja estar lá:

\footnotetext{
Preocupei-me, mas também me alegrei por ele. Finalmente encontrava-se na Nicarágua, combatendo ao lado de suas tropas. Era ali que eu queria estar. A retaguarda era importante, mas ansiava que chegasse o momento de poder participar no esforço fundamental daquela luta: o combate dentro do país. (BELLI, 2002, p. 284).
}

A condição de classe, de gênero, enfim, como já foi abordado anteriormente, a partir do entendimento de Randall (1982) e Zimmermann (2006), é determinante, sobretudo para a mulher, em diversas situações de sua vida. E, se a situação de luta já é embaraçosa por si, para a condição de mulher a dificuldade é ainda maior. Porém, não impossível a depender do empenho. Após a derrubada de Somoza, quando Belli já havia voltado para Manágua, ela observa uma parada que é organizada pelos chefes militares. Homens e mulheres marcham sob o sol, uniformizados e com um fuzil ao ombro. Alguém insinua que as mulheres não devem participar da luta armada e Belli logo se manifesta, pois acha a ideia um absurdo: "Como podiam sequer pensar nisso quando as mulheres haviam demonstrado ser tão boas combatentes quanto os homens durante a insurreição?” (BELLI, 2002, p. 315). Alguns meses depois, é decidido pelos comandantes do exército que as mulheres só devem ocupar cargos administrativos. Porém, a polícia sandinista não faz essa diferença e permite a participação de grande número de mulheres. O Ministério do Interior age da mesma forma: "Eu gostava de ver as meninas com uniformes verde-oliva e botas militares impecavelmente lustradas. Muitas delas usavam batom e até pintavam as unhas de vermelho. Eram o símbolo de um novo tempo para as mulheres de meu país”. (BELLI, 2002, p. 315).

Entre outubro e novembro de 1979, Belli viaja para vários países socialistas, acompanhando Modesto em uma delegação oficial. Na Argélia, Belli é entrevistada por mulheres jornalistas que indagam se na Nicarágua os homens afastariam as mulheres que haviam participado da guerra, da mesma forma que aconteceu na Argélia. As mulheres argelinas precisam travar uma luta diária para garantir seu espaço porque eram 
deixadas de lado constantemente pelos homens. Belli responde que a experiência da Argélia servirá para as nicaraguenses ficarem em alerta e não permitirem que isso aconteça também com elas; as nicaraguenses não iriam voltar para as cozinhas e a marginalidade: "Mal puderam dissimular sua descrença. Já veríamos, dizia sua expressão" (BELLI, 2002, p. 337). Essa descrença das mulheres argelinas é um reflexo de todo o machismo que sofrem; apesar de terem lutado lado a lado com os homens, ao término da luta, os homens querem que elas retornem ao espaço privado e não participem das decisões a serem tomadas pelo país.

Segundo Zimmermann (2006), na Nicarágua, cerca de $25 \%$ do exército guerrilheiro é composto por mulheres e um número maior auxilia o movimento pelos direitos humanos. Por isso, um dos primeiros decretos do governo sandinista é a garantia de direitos para as mulheres. Após a vitória dos sandinistas, a força de trabalho com saúde e educação é composta por $60 \%$ de mulheres. Mulheres oferecem-se como voluntárias para batalhões de reserva da milícia e a organização de defesa dos direitos humanos aumenta consideravelmente de tamanho. Tudo isso após a vitória sandinista de 1979. Questões como amamentação de bebês por mães presas, reconhecimento de paternidade, participação no exército e aborto passam a ser discutidas em movimentos organizados por mulheres. Alguns direitos são conquistados, outros são esquecidos com o tempo. Com a crise, muitas demissões acontecem e as conquistas são enfraquecidas por falta de apoio do Diretório Nacional.

Para Scott (1995), provar que as mulheres têm uma história não tem sido suficiente. Geralmente, a história das mulheres é separada da história dos homens ou se considera que elas não participaram da histórica política e econômica. Percebe-se que inúmeros são os casos de mulheres que defendem sua pátria ou, mesmo que não seja seu país de origem, identificam-se com uma causa de um determinado país e ajudam como podem, seja através de atividades mais simples ou mesmo na luta armada. Percebe-se que, independente de estarem ou não em seu país, as mulheres engajam-se na luta por uma sociedade mais justa, sem preconceitos e que proporcione uma vida de igualdades entre as pessoas. Correm riscos, esquecem a vida pessoal, muitas vezes são agredidas, estupradas ou até mortas; quando acreditam que seu país pode tornar-se um ambiente em que todos possam viver de forma igualitária, buscam esse ideal com todas as suas forças, correndo qualquer risco. Belli quase perde o contato com as filhas, arrisca suas 
vidas e passa anos em função do idealismo de ter uma Nicarágua livre dos ditadores; ela realmente deixa sua vida de lado por conta desse ideal.

\section{Considerações finais}

Ao escrever suas memórias, Belli passa a construir uma narrativa marcada pelo gênero, o que confere voz à mulher e representa uma superação das limitações e do processo de exclusão a que a mulher esteve submetida. Ao se apropriar da narrativa, a mulher questiona formas institucionalizadas de comportamento feminino e promove reflexão sobre o que foi silenciado e instaura um espaço de resistência contra as representações simbólicas socialmente fossilizadas.

Na narrativa de Belli é percebido que a mulher tem participação na construção de uma Nicarágua livre e justa, apesar de se acreditar que somente os homens têm uma participação ativa nessas situações. O engajamento feminino é real e determinante, inclusive na participação na luta armada e não somente em trabalhos considerados femininos, como assistência médica aos feridos e oferecimento de abrigo aos militantes. Esse engajamento reflete a identidade com seu país e o enfrentamento a qualquer obstáculo para libertação de sua nação.

A Nicarágua é considerada o símbolo da ditadura latino-americana e Belli não consegue ser mera expectadora das injustiças que ocorrem em seu país. Ao entrar para o sandinismo, busca realizar o sonho de viver em um país mais justo para si, suas filhas e seus irmãos nicaraguenses. Toda a experiência vivida enquanto membro da FSLN é aproveitada em suas memórias, em que há a junção de memória individual e coletiva, transformando a história da ditadura em ficção, a partir de seus relatos.

As mulheres que por algum motivo não se envolvem na luta de frente, estão envolvidas em associações e grupos que buscam livrar a Nicarágua da ditadura; anseiam por um país com condições igualitárias de vida para si e seus filhos, mostrando, assim, que a mulher é politizada e esse espírito engajado é demonstrado desde o período colonial, apesar do preconceito sofrido. A mulher mostra sua opinião e busca realizar suas ideias mostrando, assim, que a mulher participa ativamente da vida política de seu país, mesmo que essa participação seja invisibilizada pela historiografia oficial.

Revista Moara, n. 56 vol.1, ago-dez 2020 ISSN: 0104-0944 


\section{REFERÊNCIAS}

BELLI, Gioconda. O país sob minha pele: Memórias de amor e guerra. Tradução de Ana Carla Lacerda. Rio de Janeiro: Record, 2002.

CULVER, V. Woman-Warrior: Gender Identity Development of Women in the American Military. Journal of the Student Personnel Association at Indiana University, p. 64-74, 9 maio 2013. Disponível em: https://scholarworks.iu.edu/journals/index.php/jiuspa/article/view/3674. Acesso em 21 ago 2020 .

EDWARDS, Keith E.; JONES, Susan R.. Putting My Man Face On: A Grounded Theory of College Men's Gender Identity Development. Journal of College Student Development, vol. 50, $\mathrm{n}^{\mathrm{o}} \quad 2, \quad 2009$, p. 210-228. Disponível em: https://muse.jhu.edu/article/260883/pdf\#info_wrap. Acesso em: 21 ago 2020.

MATTOSO, José. A identidade nacional. Disponível em: https://civilizacaoiberica.files.wordpress.com/2010/08/jose-mattoso-a-identidadenacional-pdfrev.pdf. Acesso em 18 ago 2020.

RANDALL, Margaret. Estamos todas despertas. São Paulo: Global, 1982.

SCOTT, Joan Wallach. Gênero: uma categoria útil de análise histórica. Educação e realidade. Porto Alegre, vol. 20, $\mathrm{n}^{\circ}$ 2, p. 71-99, jul./dez., 1995. Disponível em: https://direito.mppr.mp.br/arquivos/File/SCOTTJoanGenero.pdf. Acesso em 12 ago 2020.

WALBY, Sylvia. A mulher e a nação. In: BALAKRISHMAN, Gopal. Um mapa da questão nacional. Rio de Janeiro: Contraponto, 2000.

YUVAL-DAVIS, Nira. Nationalism, racismo and gender relations. Working Papers General Series 18830, International Institute of Social Studies of Erasmus University Rotterdam (ISS), $\mathrm{n}^{\mathrm{o}}$ 130. July. 1992. Disponível em: file://C:/Users/hairt/Downloads/wp130\%20(4).pdf. Acesso em 21 ago 2020.

ZIMMERMANN, Matilde. A Revolução Nicaraguense. São Paulo: Editora UNESP, 2006. 
ZINANI, Ceci Jeanine Albert. História da Literatura: questões contemporâneas. Caxias do Sul, RS: EDUCS, 2010.

Revista Moara, n. 56 vol.1, ago-dez 2020 ISSN: 0104-0944 